\title{
Closing the dimethyl sulfide budget in the tropical marine boundary layer during the Pacific Atmospheric Sulfur Experiment
}

\author{
S. A. Conley ${ }^{1}$, I. Faloona ${ }^{1}$, G. H. Miller ${ }^{2}$, D. H. Lenschow ${ }^{3}$, B. Blomquist ${ }^{4}$, and A. Bandy ${ }^{5}$ \\ ${ }^{1}$ Department of Land, Air and Water Resources, University of California, Davis, CA, USA \\ ${ }^{2}$ Department of Applied Science, University of California, Davis, CA, USA \\ ${ }^{3}$ National Center for Atmospheric Research, Boulder, CO, USA \\ ${ }^{4}$ Department of Oceanography, University of Hawaii, Honolulu, HI, USA \\ ${ }^{5}$ Department of Chemistry, Drexel University, Philadelphia, PA, USA
}

Received: 3 July 2009 - Published in Atmos. Chem. Phys. Discuss.: 14 August 2009

Revised: 29 October 2009 - Accepted: 2 November 2009 - Published: 17 November 2009

\begin{abstract}
Fourteen research flights were conducted with the National Center for Atmospheric Research (NCAR) C-130 near Christmas Island $\left(2^{\circ} \mathrm{N}, 157^{\circ} \mathrm{W}\right)$ during the summer of 2007 as part of the Pacific Atmospheric Sulfur Experiment (PASE). In order to tightly constrain the scalar budget of DMS, vertical eddy fluxes were measured at various levels in the marine boundary layer (MBL) from $\sim 30 \mathrm{~m}$ to the top of the mixed layer $(\sim 500 \mathrm{~m})$ providing improved accuracy of the flux divergence calculation in the DMS budget. The observed mean mole fraction of DMS in the MBL exhibited the well-known diurnal cycle, ranging from 50-95 pptv in the daytime to $90-110$ pptv at night. Contributions from horizontal advection are included using a multivariate regression of all DMS flight data within the MBL to estimate the mean gradients and trends. With this technique we can use the residual term in the DMS budget as an estimate of overall photochemical oxidation. Error analysis of the various terms in the DMS budget indicate that chemical losses acting on time scales of up to $110 \mathrm{~h}$ can be inferred with this technique. On average, photochemistry accounted for $\sim 7.4 \mathrm{ppthr}^{-1}$ loss rate for the seven daytime flights, with an estimated error of $0.6 \mathrm{ppthr}^{-1}$. The loss rate due to expected $\mathrm{OH}$ oxidation is sufficient to explain the net DMS destruction without invoking the action of additional oxidants (e.g., reactive halogens.) The observed ocean flux of DMS averaged $3.1( \pm 1.5) \mu \mathrm{mol} \mathrm{m}^{-2} \mathrm{~d}^{-1}$, and generally decreased throughout the sunlit hours. Over the entire mission, the horizontal advection contribution to the overall bud-
\end{abstract}

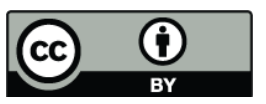

Correspondence to: S. A. Conley (saconley@ucdavis.edu) get was merely $-0.1 \mathrm{ppthr}^{-1}$, indicating a mean atmospheric DMS gradient nearly perpendicular to the east-southeasterly trade winds and the chlorophyll gradient in the equatorial upwelling ocean. Nonetheless, horizontal advection was a significant term in the budget of any given flight, ranging from -1.2 to $2.5 \mathrm{ppt} \mathrm{hr}^{-1}$, indicating a patchy and variable surface seawater DMS distribution, and thus needs to be accounted for in budget studies.

\section{Introduction}

Dimethyl sulfide (DMS) is an important factor in global climate because it is a source of sulfate which can thus alter the $\mathrm{pH}$ and radiative properties of condensed phases (Faloona, 2009). DMS has also been implicated as the agent of a negative feedback mechanism that, in principle, could counteract man made global warming (Charlson et al., 1987). Phytoplankton are the primary source of DMS in the marine troposphere, and DMS is a major source of cloud condensation nuclei (CCN) in that same region (Pandis et al., 1994). Potentially, if phytoplankton productivity increased in response to a warming ocean, there would be a corresponding increase in the flux of DMS from the ocean to the atmosphere. More DMS would lead to an increase in the number of cloud condensation nuclei available, resulting in brighter, more persistent clouds and a corresponding reduction in the shortwave radiation absorbed by the surface (Charlson et al., 1987). Therefore, understanding the DMS budget in the remote marine troposphere can be important for global climate prediction. This work attempts to close the budget of DMS in the remote marine boundary layer (MBL) without relying on

Published by Copernicus Publications on behalf of the European Geosciences Union. 


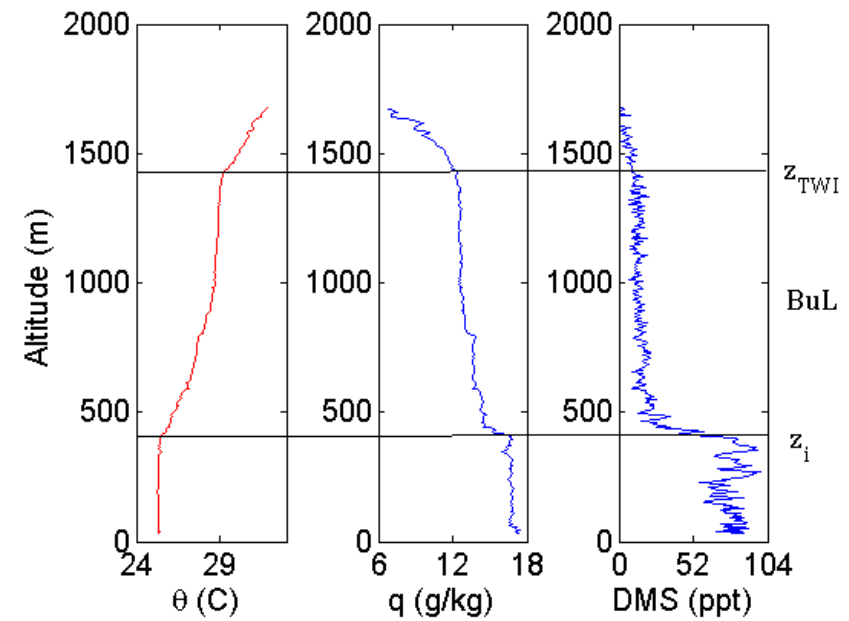

Fig. 1. RF03 MBL Structure Observed During PASE. $z_{i}$ is the mean height of the weak MBL inversion and $z_{\mathrm{TWI}}$ denotes the stronger trade wind inversion aloft. Horizontal axes are potential temperature, water vapor, and DMS, respectively.

parameterizations of surface or entrainment fluxes. Through carefully designed flight tracks, the fluxes of DMS from the ocean to the MBL, and from the MBL to the overlying buffer layer $(\mathrm{BuL})$ were physically measured and used to interpret its budget in the boundary layer.

The atmospheric budget of DMS in the MBL is controlled by four principal processes: efflux from the ocean, vertical transport into the BuL, horizontal advection, and photochemical destruction. Following Kowalski and SerranoOrtiz (2007), the mixing ratio budget can be written as:

$$
\frac{\partial c}{\partial t}+\nabla \cdot(\boldsymbol{u} c)=-L
$$

where $c$ is the DMS mole fraction, which is the sum of the fluctuating component, $\mathrm{c}^{\prime}$, and its ensemble mean value $C$, $\boldsymbol{u}$ is the full three-dimensional turbulent wind field, and $L$ represents the mean photochemical loss rate of DMS. In this work, primed variables indicate departures from the mean and capitals or overbars indicate mean values. Several assumptions, listed below, are frequently made in order to simplify budget calculations in the boundary layer.

1. The flow is incompressible; $\nabla \cdot \boldsymbol{u}=0$, where $\boldsymbol{u}=(u, v, w)$.

2. The turbulence is horizontally homogeneous, implying here that there is no horizontal variation in any of the turbulent second moment quantities such as the horizontal turbulent fluxes, i.e. $\frac{\partial}{\partial x}\left(\overline{u^{\prime} c^{\prime}}\right)=0 ; \frac{\partial}{\partial y}\left(\overline{v^{\prime} c^{\prime}}\right)=0$

With these assumptions, we obtain a budget equation for the mean DMS mole fraction in the marine boundary layer:

$\frac{\partial C}{\partial t}=-U \frac{\partial C}{\partial x}-V \frac{\partial C}{\partial y}-\frac{\partial}{\partial z}\left(\overline{w^{\prime} c^{\prime}}\right)-L$
Fourteen research flights were conducted with the National Center for Atmospheric Research (NCAR) C-130 near Christmas Island $\left(2^{\circ} \mathrm{N}, 157^{\circ} \mathrm{W}\right)$ during the summer of 2007 as part of the Pacific Atmospheric Sulfur Experiment (PASE). In order to tightly constrain the scalar budget of DMS, fluxes were measured at various levels in the marine boundary layer (MBL) from near the surface $(\sim 30 \mathrm{~m})$ to the top of the mixed layer $(\sim 500 \mathrm{~m})$ providing improved accuracy of the flux divergence calculation in the DMS budget. Traditionally, measurement of the surface flux and the flux at the top of the MBL have been challenging to obtain and previous researchers have resorted to parameterizations of these processes in attempts to close the budget (Nowak et al., 2001). PASE was a unique photochemical experiment in that the flight legs were structured such that each stack (approximately 3 per flight) included $30 \mathrm{~min}$ legs at four heights of interest: near the surface, the middle of the mixed layer, near the top of the $\operatorname{MBL}\left(z_{i}\right)$, and in the lower BuL. The BuL is the intermittently turbulent, conditionally unstable region often containing trade-wind cumuli that lies just above the MBL and below the trade-wind inversion which was typically found at $1.5 \mathrm{~km}$ during PASE. Turbulent vertical fluxes were calculated from eddy covariance, i.e. Flux $=\left(\overline{w^{\prime} c^{\prime}}\right)$. During PASE, all of the terms in Eq. (2) except for $L$ were measured directly.

\section{Boundary layer structure}

During PASE, the mean MBL potential temperature $(\Theta)$ only varied between $296.5 \mathrm{~K}$ and $298.0 \mathrm{~K}$, and the mean sea surface temperature (SST) between $298.4 \mathrm{~K}$ and $300.5 \mathrm{~K}$. This results in nearly constant surface sensible and latent heat fluxes and an MBL with virtually no diurnal changes. Over the tropical oceans, a three-layer atmospheric structure typically exists with a turbulent MBL of roughly $500 \mathrm{~m}$ depth, overlain by an intermittently turbulent BuL of approximately $1000 \mathrm{~m}$ depth, overlain by the free troposphere (FT). Separating the MBL from the BuL is a weak temperature inversion, while a much stronger trade wind inversion (TWI) separates the BuL from the FT. Most scalars within the MBL are well mixed, resulting in a mixing ratio profile that is nearly constant with altitude throughout the MBL. DMS rapidly falls off to near zero above the MBL top. This structure was previously documented during ACE1 (Russell et al., 1998). An example of this structure from research flight \#3 (RF03) of PASE is shown in Fig. 1. The figure shows considerably more variability in the DMS signal than in either water vapor or potential temperature, which is primarily a consequence of its relatively large flux with respect to its atmospheric abundance. 

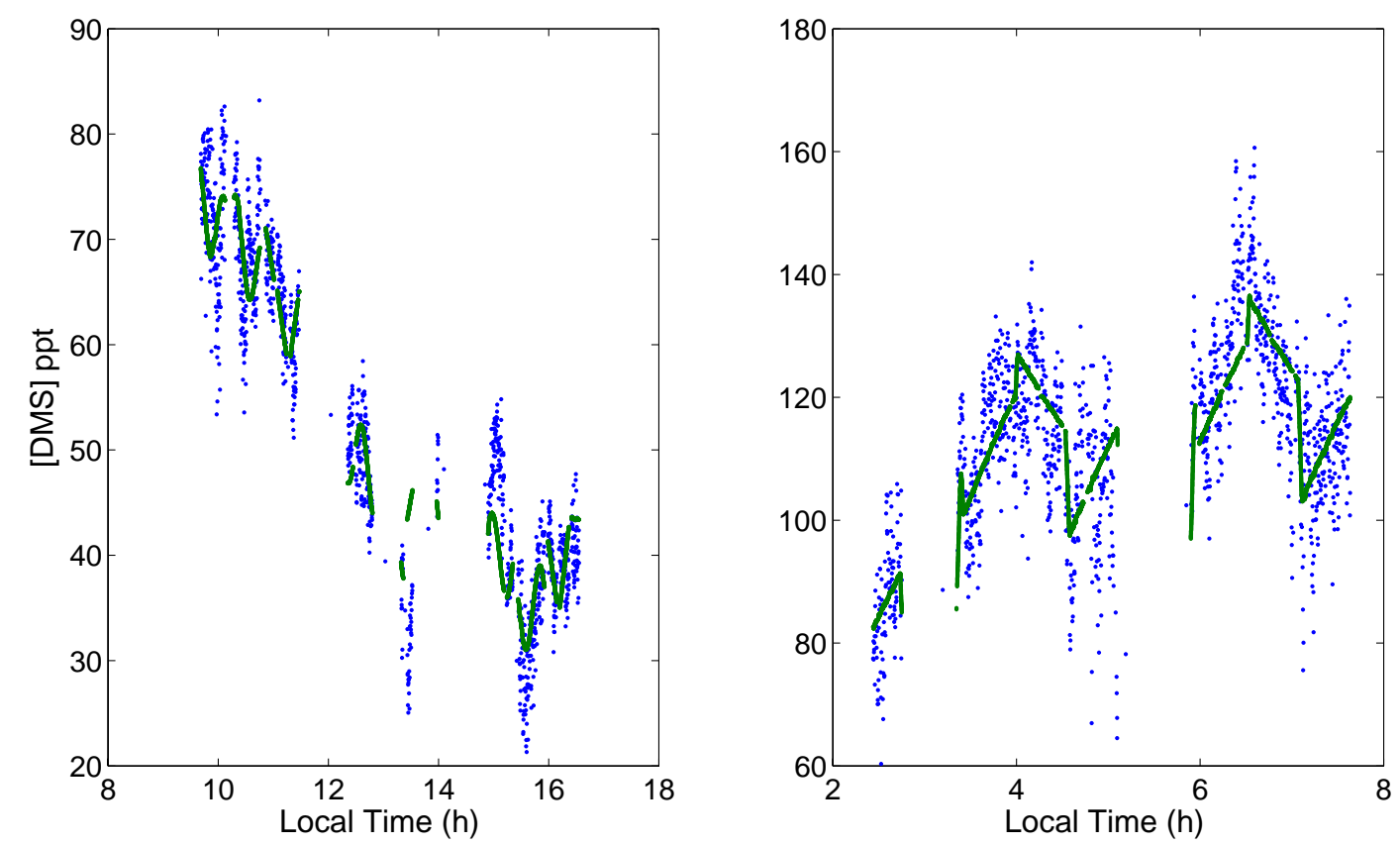

Fig. 2. Multiple regression fit of the time series of DMS observed in the marine boundary layer during RF02 (left, daytime) and RF13 (right, nighttime). Actual data points in blue, fit in green.

\section{Methods}

DMS was measured by an analytic method called atmospheric pressure ionization mass spectrometry using isotopically labeled standards (APIMS-ILS). This technique has been shown to be viable for calculating airborne vertical fluxes via eddy covariance (Bandy et al., 2002; Faloona et al., 2005). The measurement has some attenuation at higher frequencies, but the amplitude was corrected using the expression obtained by Blomquist et al. (2009) in laboratory studies. Initially, the intent was to fly 30-min Lagrangian circles, and drift with the mean MBL flow over time to minimize the contribution from horizontal advection. Difficulties arose with the circle patterns because the aircraft frequently passed through its own exhaust, which rapidly mixed vertically throughout the MBL. While this contamination was not significant for DMS measurements, it was for other scalars such as ozone and $\mathrm{SO}_{2}$. Therefore, the circles were abandoned and a chevron pattern consisting of two $15 \mathrm{~min}$ legs with a $60^{\circ}$ turn in the middle was flown instead. The orientation of the legs was chosen so that the mean wind bisected the angle of the chevron pattern. Unfortunately, this pattern resulted in substantial drift relative to the air mass being sampled. To correct for the non-Lagrangian sampling and the resultant drift of the DMS concentration over time (due to advection), a multi-variable linear regression was performed on all of the MBL data collected during level legs on each of the flights.

Closing the budget (Eq. 2) requires also the time rate of change of DMS and its horizontal gradients. To estimate these terms, we used a multiple regression fit, assuming the DMS mole fraction to be a function of time and space, as described below. Previous measurements of DMS on Christmas Island (Bandy et al., 1996) demonstrated a consistent sinusoidal diurnal cycle in the concentration of DMS with a morning maximum around 04:30 a.m. (local) and an afternoon minimum around 04:30 p.m. The DMS concentration was thus assumed to be a function of the position, $x, y$, and $z$ (all measured in meters) and time $t$ (measured in hours), i.e. $c=f(x, y, z, t)$. Expanding $f$ in a Taylor series about the spatial coordinates, including only the first order terms, and assuming the time dependence to be the combination of a diurnal sinusoid and a linear drift leads to:

$c=\beta_{0}+\beta_{1} x+\beta_{2} y+\beta_{3} z+\beta_{4} t+\beta_{5} \cdot \sin \left(\frac{2 \pi(t-\phi)}{24}\right)$

The coefficients $\left(\beta_{1}-\beta_{5}\right)$ represent the DMS derivatives in space and time. The phase term $(\phi)$ represents the time of day when the sinusoidal component of the variation crosses zero, around 10:30 a.m. The solution is then approached as a least squares problem using the 1-s data for both the DMS mole fraction as well as the position and time compiled from all the level legs of the flight below the inversion height, $z_{i}$.

Visually, the fit reproduces the flight variation well (Fig. 2). For a quantitative measure of the fit, we calculated the coefficient of determination, $R^{2}$, for each flight, defined as

$R^{2}=1-\frac{\sum\left(c_{i}-m_{i}\right)^{2}}{\sum\left(c_{i}-\bar{c}\right)^{2}}$, 
Table 1. Terms in the advection calculation. Columns are as follows: flight number, horizontal advection $\left(\mathrm{ppthr}^{-1}\right)$, zonal DMS gradient (ppt deg ${ }^{-1}$ ), meridional DMS gradient (ppt deg ${ }^{-1}$ ), vertical DMS gradient $\left(\mathrm{ppt} \mathrm{km}^{-1}\right)$, mean zonal wind $\left(\mathrm{km} \mathrm{hr}^{-1}\right)$, and mean meridional wind $\left(\mathrm{km} \mathrm{hr}^{-1}\right)$.

\begin{tabular}{lrrrrrr}
\hline $\mathrm{RF}$ & $\mathrm{Adv}$ & $\partial_{x} \mathrm{C}$ & $\partial_{y} \mathrm{C}$ & $\partial_{z} \mathrm{C}$ & $\mathrm{U}$ & $\mathrm{V}$ \\
\hline 2 & 0.5 & 3.4 & 13.0 & -15.3 & -26.1 & 2.8 \\
3 & -0.8 & 1.6 & 9.3 & -19.0 & -23.2 & 14.0 \\
5 & 2.0 & 5.9 & 8.4 & 6.0 & -36.4 & -1.5 \\
8 & -0.5 & 0.4 & 7.0 & -10.6 & -24.4 & 9.9 \\
11 & 2.3 & 5.9 & -8.5 & -12.6 & -28.0 & 10.3 \\
12 & -1.1 & 6.3 & 22.0 & -7.5 & -26.2 & 13.1 \\
14 & -1.2 & -0.5 & 27.6 & -27.6 & -36.5 & 4.2 \\
Average & 0.2 & 3.3 & 11.3 & -12.3 & -28.7 & 7.6 \\
6 & 1.8 & 6.5 & 1.9 & -15.6 & -30.8 & 1.3 \\
13 & -2.5 & 0.0 & 17.5 & -46.1 & -37.5 & 15.8 \\
Average & -0.4 & 3.2 & 9.7 & -30.9 & -34.1 & 8.5 \\
\hline
\end{tabular}

where $c_{i}$ are the actual values of the DMS mole fraction in the time series and $m_{i}$ are the fitted values of the DMS mole fraction. The numerator is the sum of the squares of the departures of the fit prediction from the actual mole fraction, while the denominator is the variance in the observed DMS values. For the day flights, the average $R^{2}$ is 0.76 while for RF13 (night flight) it drops to 0.49. This apparent loss of fit quality is probably not indicative of a deterioration of the quality of fit, but rather is a result of the diminished atmospheric variability of DMS (the denominator in Eq. 4) during the night flights. Day and night, random instrumental noise remains the same while atmospheric variability is greatly reduced around the diurnal maximum and minimum. Although RF06 and RF13 are labeled night flights, they were actually flown half before and half after sunrise to study the effects of twilight photochemistry, and are therefore centered about the predawn maximum ( 04:30 a.m.).

The gradients in each of the horizontal directions $\left(\beta_{1}, \beta_{2}\right)$ and the vertical $\left(\beta_{3}\right)$ for the PASE flights are listed in Table 1 . The horizontal gradient of DMS was fairly consistent, with all but one flight (RF14) indicating higher concentrations to the east, and every flight but RF08 showing higher concentrations to the north. Since the mean wind was typically east-southeasterly, the advection was generally made up of a balance between meridional and zonal components of opposite sign.

\subsection{Flux divergence}

In addition to the mean temporal and spatial changes the scalar budget equation includes two remaining terms: vertical flux divergence and photochemical loss. In principle, the contribution to the mean scalar budget from the flux divergence in Eq. (1) is $-\nabla \cdot(\overline{c \boldsymbol{u}})$, where the overbar indicates
Reynolds averaging. This deceivingly simple term is complicated by the fact that measurements of wind speeds include a significant component of atmospheric variability due to turbulence in the MBL. Breaking down the flux divergence term into each of its mean and fluctuating components leads to:

$$
\begin{aligned}
-\nabla \cdot(\overline{c \boldsymbol{u}})= & -\frac{\partial}{\partial x}(\bar{u} \cdot \bar{c})-\frac{\partial}{\partial x}\left(\overline{u^{\prime} c^{\prime}}\right)-\frac{\partial}{\partial y}(\bar{v} \cdot \bar{c}) \\
& -\frac{\partial}{\partial y}\left(\overline{v^{\prime} c^{\prime}}\right)-\frac{\partial}{\partial z}(\bar{w} \cdot \bar{c})-\frac{\partial}{\partial z}\left(\overline{w^{\prime} c^{\prime}}\right)
\end{aligned}
$$

With the assumption that the flow is incompressible, this reduces to:

$$
\begin{aligned}
-\nabla \cdot(\overline{c \boldsymbol{u}})= & -\bar{u} \frac{\partial \bar{c}}{\partial x}-\bar{v} \frac{\partial \bar{c}}{\partial y}-\bar{w} \frac{\partial \bar{c}}{\partial z}-\frac{\partial}{\partial x}\left(\overline{u^{\prime} c^{\prime}}\right) \\
& -\frac{\partial}{\partial y}\left(\overline{v^{\prime} c^{\prime}}\right)-\frac{\partial}{\partial z}\left(\overline{w^{\prime} c^{\prime}}\right)
\end{aligned}
$$

The contributions to this overall flux divergence from the horizontal turbulent flux terms were measured to be nearly two orders of magnitude smaller than those from the horizontal mean wind terms. Therefore we neglect the horizontal turbulent flux terms. Finally, realizing that vertical mean advection is countered for the most part by entrainment, as there are no discernable changes in boundary layer height over the course of a typical flight, we further assume that the vertical mean advection is captured in the entrainment flux. These simplifications leave the flux divergence in Eq. (1) as:

$-\nabla \cdot(\overline{c \boldsymbol{u}})=-\bar{u} \frac{\partial \bar{c}}{\partial x}-\bar{v} \frac{\partial \bar{c}}{\partial y}-\frac{\partial}{\partial z}\left(\overline{w^{\prime} c^{\prime}}\right)$

Each of these terms is considered in detail in the next sections.

\subsection{Horizontal advection}

Figure 3 illustrates the evolution of the chlorophyll-a concentration in the ocean around Christmas Island during August 2007 in response to a developing weak La Niña. The SeaWiFS data shows that the concentration in the equatorial cold tongue increased substantially between the first and last week of August. Chlorophyll is frequently used as a weak proxy for DMS concentration (Simo and Dachs, 2002) and thus provides evidence that the region is horizontally inhomogeneous with respect to DMS production in the ocean. The PASE flights were typically within or near the equatorial cold tongue and the variance in the horizontal is most likely related to the varying levels of productivity indicated in this image. However, the persistent gradient in the in-situ data is directed to the north-northeast, and therefore appears to have a complex spatial relationship to the local chlorophyll patterns in the ocean.

The first two research flights consisted of Lagrangian circles while later flights used a chevron pattern. Each of these flight techniques resulted in differing levels of success tracking the mean wind. Calculation of the horizontal advection 


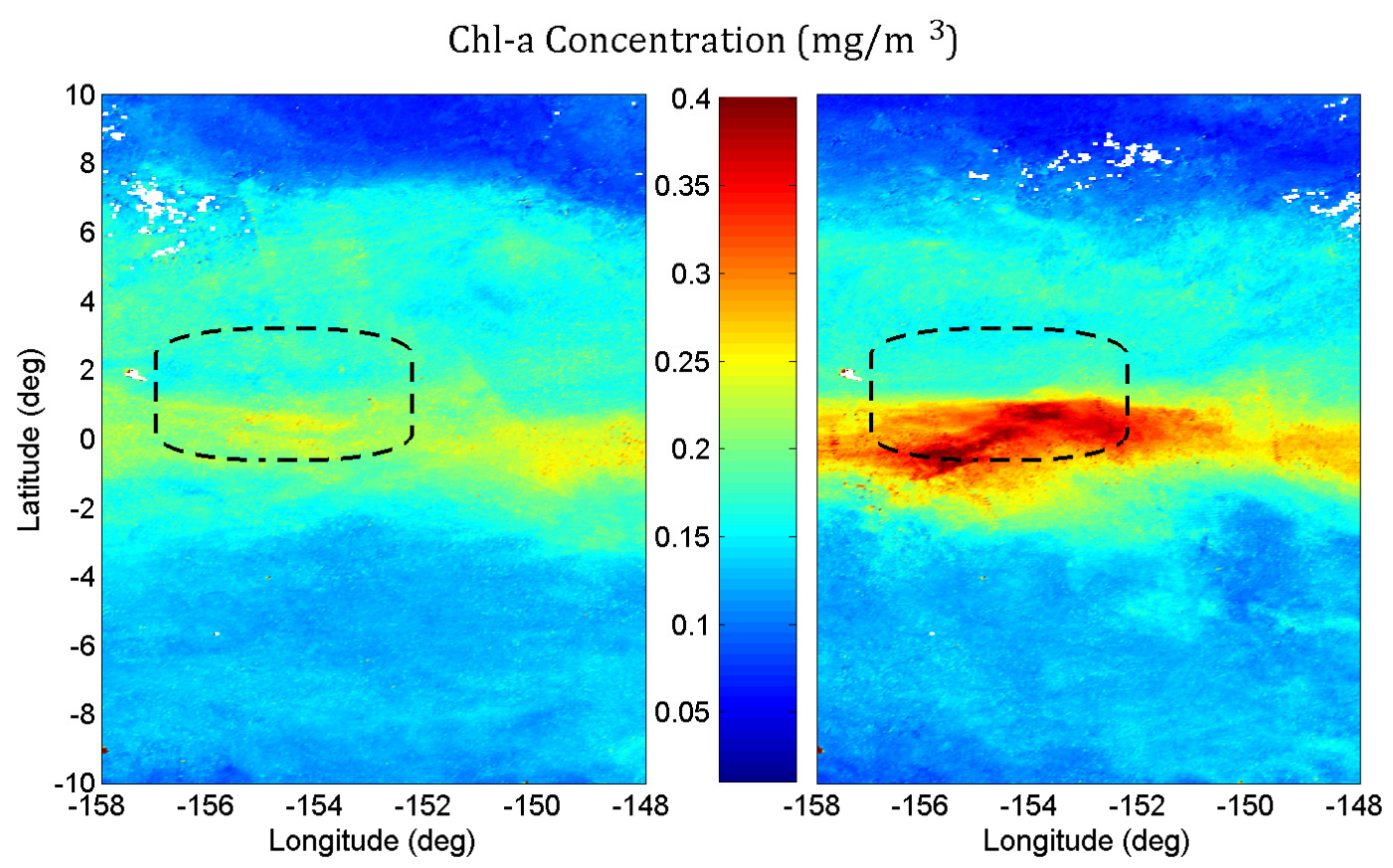

Fig. 3. PASE research flight area (dashed rectangle) in relation to the regional chlorophyll-a patterns for August 2007. The panel on the left is a composite of the first two weeks of August and the panel on the right is the last two weeks of August. The prevailing MBL winds during PASE were east-southeasterly with an average speed of $8 \mathrm{~m} / \mathrm{s}$.

budget term involves two steps: First, the zonal and meridional gradients in the DMS mole fraction are estimated using the multiple regression fit as described above. Then, the mean wind is calculated by averaging each wind component measured during the legs flown within the boundary layer. The average wind direction during the PASE flights was $105^{\circ}$ from North while the average DMS gradient vector was oriented to the NNE $\left(17^{\circ}\right)$ - nearly perpendicular to the mean wind. Thus, on average, advection contributes nothing to the DMS budget. Nevertheless inclusion of this term was important for each flight because it contributed between 10-40\% of the observed DMS rate of change.

\subsection{Vertical flux divergence}

The relatively insoluble DMS volatilizes from the sea surface to the lowest layers of the MBL, and is turbulently mixed throughout the MBL and carried to the BuL by convection. As can be seen in Fig. 1, its concentration drops rapidly with altitude above the MBL so very little DMS survives to enter the free troposphere unless it is delivered there rapidly by deep convection. Flux divergence was estimated from the turbulent vertical flux (via eddy covariance) measured at various levels within the MBL. Figure 4 shows the mean co-spectra of DMS mole fraction and vertical wind speed grouped by approximate height above the surface and averaged over all of the PASE research flights. The labels correspond to the location within the MBL where the measurement was taken and roughly translate to the top and bottom of the MBL. As would be expected in the MBL, the cospectral peak is shifted to the left (lower wavenumber, larger eddies) as we move up in the MBL from the lower boundary layer (LBL) to the top of the boundary layer (TBL).

A $200 \mathrm{~s}(22 \mathrm{~km})$ averaging interval was selected by examining the complete co-spectra to find a frequency cut-off that would capture most of the flux without including mesoscale variations. As can be seen in Fig. 4, the contribution from wavenumbers below the cutoff $\left(0.046 \mathrm{~km}^{-1}\right)$ is small compared with wavenumbers above the cutoff. This filter width is similar to but a little larger than that used during DYCOMSII (Faloona et al., 2005). The longer filter width was chosen to capture all of the relevant scales evident in Fig. 4. The larger scales in PASE are possibly the result of convective roll structures that were often evident in cloud streets traversing the study area.

The vertical turbulent flux is determined using eddy covariance, or averaging the product of vertical wind perturbations and DMS mole fraction perturbations, i.e. $\left(\overline{w^{\prime} c^{\prime}}\right)$ over each $22 \mathrm{~km}$ interval of a level flight leg. Since DMS and $w$ are measured at different places on the airplane, and each instrument has its own characteristic delays, it is necessary to apply a time offset to synchronize the measurements. Since the DMS instrument has its own clock, this lag will vary from flight to flight and, in principle, could even drift within a given flight. The appropriate lag time was determined by examining the phase angle between DMS and $w$ (Fig. 5), with the assumption that the actual DMS and $w$ are in phase. 


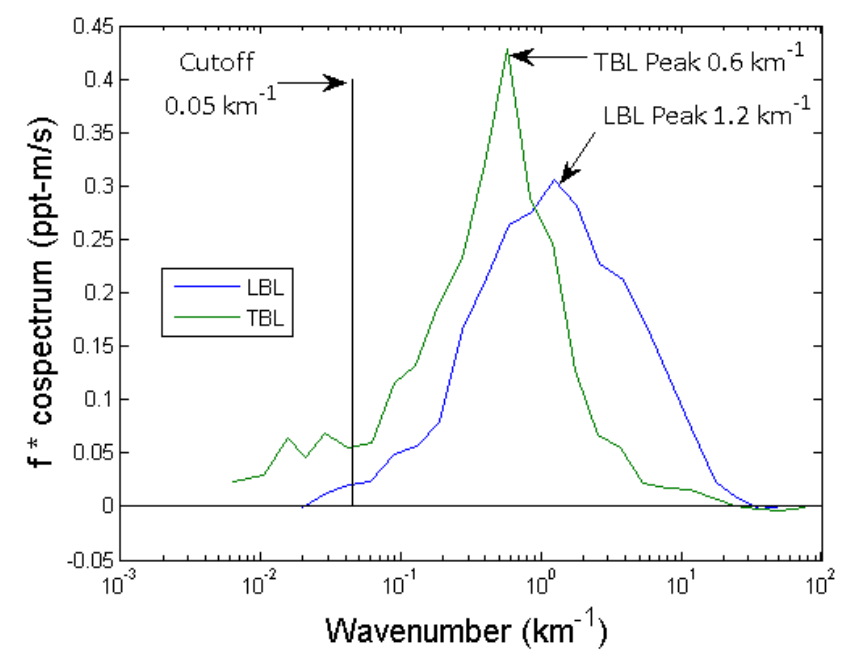

Fig. 4. Averaged co-spectra of DMS with vertical wind speed. The flight legs are averaged into lower levels (LBL) flown below $\sim 50 \mathrm{~m}$, top of the boundary layer (TBL) flown around $400 \mathrm{~m}$.

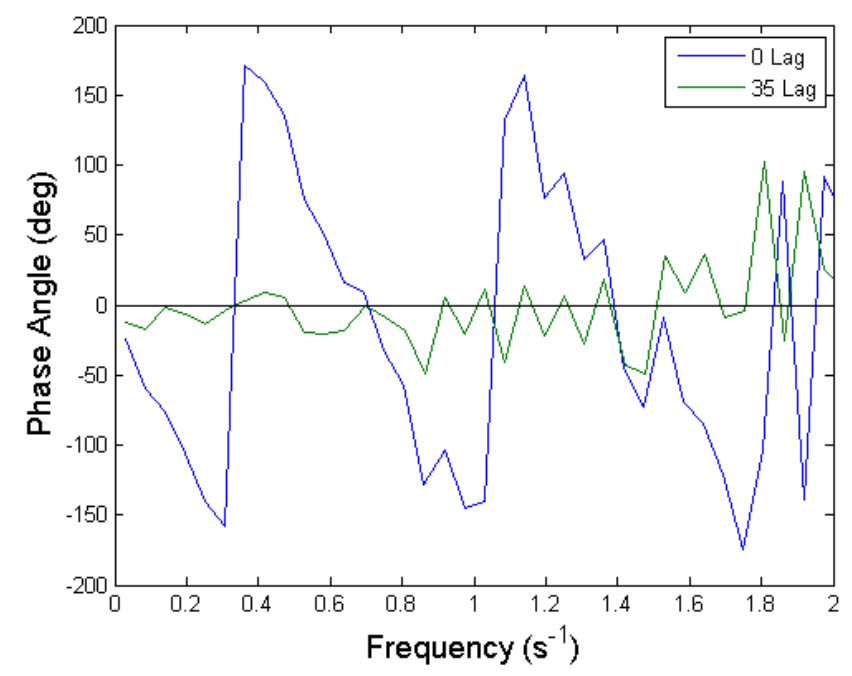

Fig. 5. Phase angle spectrum of DMS vs. $w$ for leg 7 of RF03. Following the blue line, the difference between the first two zero crossings is $0.72 \mathrm{hz}$, which equates to $1.4 \mathrm{~s}$, or 35 samples (at the high rate sampling of $25 \mathrm{hz}$ ). The green line shows the phase lag when the DMS signal is consequently shifted by 35 samples.

Since the DMS flux is usually largest for the LBL legs, those legs were used to determine the lag time for each flight stack. The average lag time for the PASE flights was $\sim 1.4 \mathrm{~s}$. Figure 6 shows the lag value determined for the same leg by maximizing the correlation coefficient instead. The difference of 1 sample $(40 \mathrm{~ms})$ makes a negligible difference in the flux.

In addition to correcting for the time lag, a correction is made for the inability of the DMS instrument to measure high-frequency variations. The principal source of frequency

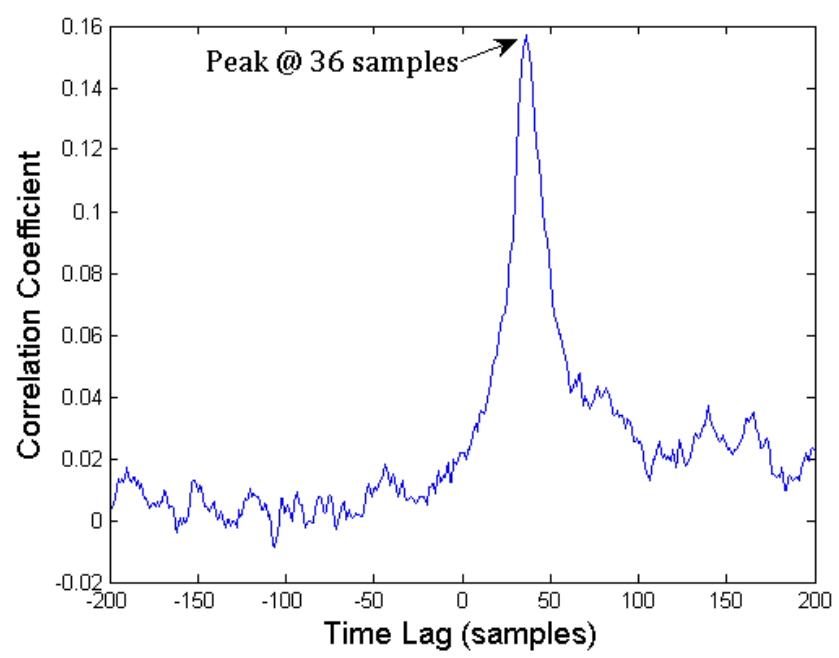

Fig. 6. Correlation coefficient between DMS and vertical wind as a function of time lag for leg 7 (flown at $\sim 30 \mathrm{~m}$ altitude) of RF03. The maximum correlation at a lag of 36 samples $(1.44 \mathrm{~s})$ is consistent with the lag time derived from the phase angle spectrum.

attenuation is believed to be the Nafion ${ }^{\circledR}$ dryer and subsample tubing leading to the ion source. An empirical study of APIMS frequency response using an identical dryer and similar flow rates was performed by Blomquist et al. (2009). The empirical response function from this study is used here to correct for high frequency losses in the aircraft inlet and dryer. We divide the cospectrum by the square root of the response function to obtain the estimated true covariance. In most cases the correction is less than 5\%. The empirical response function used was (Blomquist et al., 2009):

$\Phi^{2}(f)=\exp \left(-0.557 f^{0.917}\right)$.

The actual flux values (in frequency space) were divided by the square root of the above correction function to determine the corrected cospectra, which was then plotted versus wavenumber.

The final correction made to the flux involves correcting for temporal changes in the flux throughout the day. Because of a gradual decrease in the surface fluxes observed throughout each day, and because the difference between the BuL and MBL concentration changes as well, the fluxes throughout the MBL decreased systematically during the course of each flight. Every stack (consisting of three legs: MBL, TBL, LBL) spanned nearly two hours and thus depending on the sequencing of the legs this temporal trend could lead to a significant error in the measured divergence. The fluxes were corrected by fitting a line to the flux versus time at each level and then correcting the fluxes measured for each stack to the center time of the stack. In practice this correction resulted in a small change to the divergence term in the budget $(\sim 10 \%)$. 
Table 2. DMS budget terms for the flights for which they could be measured. Columns are defined from left to right as follows: observed rate of change, vertical flux divergence, horizontal advection, photochemical loss required to balance budget (L in Eq. 2), and loss to reaction with $\mathrm{OH}$, all in units of $\mathrm{ppt} \mathrm{hr}^{-1}$. The remaining columns are entrainment velocity $\left(\mathrm{cm} \mathrm{s}^{-1}\right)$, mean MBL DMS concentration (ppt), surface flux and flux into the overlying buffer layer $\left(\mu \mathrm{mol} \mathrm{m}{ }^{-2} \mathrm{~d}^{-1}\right)$. Numbers in parentheses are error estimates. OH was not measured on RF06 but was estimated by interpolating the measured values as a function of time from the other flights.

\begin{tabular}{lrrrrrrrrr}
\hline RF & Obs & Div & Adv & Chem & OH & $\mathrm{V}_{\mathrm{e}}$ & {$[\mathrm{DMS}]$} & $\begin{array}{c}\text { Surf } \\
\text { Flux }\end{array}$ & $\begin{array}{c}\text { BuL } \\
\text { Flux }\end{array}$ \\
\hline 2 & & & & & & & & & \\
& & & & & & & & & \\
3 & $-6.0(0.4)$ & $1.9(0.2)$ & $-0.8(0.1)$ & $-7.1(0.4)$ & -7.0 & 1.0 & 66.9 & 2.3 & 1.4 \\
5 & $-4.7(0.7)$ & $4.1(0.3)$ & $2.0(0.1)$ & $-10.9(0.7)$ & -10.8 & 1.4 & 69.0 & 3.7 & 2.0 \\
8 & $-5.6(0.3)$ & $0.8(0.3)$ & $-0.5(0.1)$ & $-5.8(0.4)$ & -5.5 & 1.7 & 56.3 & 2.8 & 2.4 \\
11 & $-5.9(0.4)$ & $1.3(1.4)$ & $2.3(0.1)$ & $-9.5(1.4)$ & -6.4 & & 74.5 & 2.9 & 2.6 \\
12 & $-5.9(0.4)$ & $1.5(0.3)$ & $-1.1(0.1)$ & $-6.3(0.5)$ & -7.0 & 3.5 & 52.5 & 2.6 & 1.8 \\
14 & $-7.7(0.4)$ & $-0.8(0.4)$ & $-1.2(0.1)$ & $-5.7(0.5)$ & -10.7 & 1.0 & 94.1 & 1.8 & 2.3 \\
Avg & -5.8 & 1.4 & 0.2 & -7.4 & -7.8 & 1.7 & 66.2 & 2.6 & 2.0 \\
& & & & & & & & & \\
6 & $-0.8(0.1)$ & $-0.2(0.6)$ & $1.8(0.1)$ & $-2.4(0.7)$ & -2.2 & 1.6 & 87.3 & 2.6 & 2.8 \\
13 & $-1.6(0.2)$ & $3.2(0.6)$ & $-2.5(0.1)$ & $-2.2(0.7)$ & -3.4 & 2.4 & 112.9 & 5.8 & 4.2 \\
Avg & -1.2 & 1.5 & -0.4 & -2.3 & -2.8 & 2.0 & 100.1 & 4.2 & 3.5 \\
\hline
\end{tabular}

\section{Results and discussion}

The observed mean DMS mole fraction in the MBL exhibited the well-known diurnal cycle, ranging from $\sim 65 \mathrm{pptv}$ in the daytime (roughly 08:00 a.m. to 04:00 p.m. local time) to $100 \mathrm{pptv}$ at night (roughly 03:00 a.m. to sunrise). Table 2 shows the DMS budget during the PASE research flights. Figure 7 shows the vertical turbulent flux of DMS as a function of height and time. The black line depicts the slope of the flux divergence, which for this flight equates to an MBL DMS source of $1.9 \mathrm{ppthr}^{-1}$. Some of the flights were not well-suited for a budget analysis and were excluded from the table. Among those, RF04 was a cloud penetration flight over a much larger region than the other flights. RF07 focused on the surface layer but lacked sufficient flux measurements through the rest of the MBL to allow a reasonable estimate of divergence. Problems with the airplane's inertial navigation system during RF09 and RF10 rendered the wind measurements unreliable, and problems with the DMS instrumentation excluded RF01. Each of the significant budget terms for the remaining MBL flights are listed in Table 2.

The columns in Table 2 relate to the terms in Eq. 2 and contain all the significant factors that lead to a change of DMS mixing ratio in the MBL. From Table 2, the average photochemical loss rate during the day flights is $7.4 \mathrm{ppt} \mathrm{hr}^{-1}$. Assuming the photochemical loss term is a first-order chemical reaction rate coefficient multiplied by the DMS mole fraction, the average loss rate for the daytime flights in Table 2 is $2.6 \times 10^{-5} \mathrm{~s}^{-1}$. This is considerably less than the maximum value of the unknown first-order loss rate estimated on the coast of Hawaii of $6.5 \times 10^{-5} \mathrm{~s}^{-1}$ (De Bruyn et al., 2006).

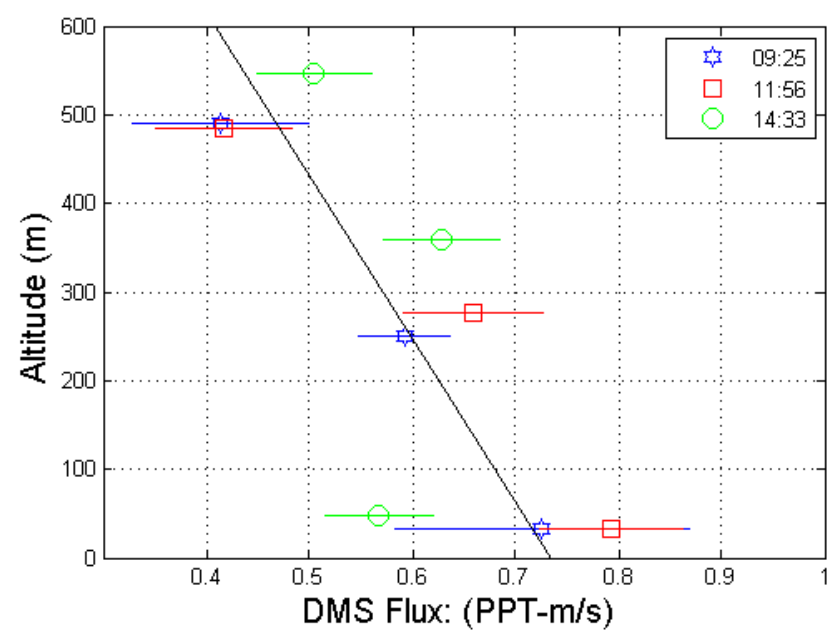

Fig. 7. DMS flux profile for RF03. The colors (red, blue \& green) correspond to the three stacks of MBL legs flown in the morning, afternoon and late afternoon.

We assume that the dominant chemical loss mechanism for DMS in the remote marine boundary layer is reaction with hydroxyl $(\mathrm{OH})$. Because $\mathrm{OH}$ was in fact measured during most of the PASE flights, we can gain some confidence in the budget technique by comparing the expected loss to $\mathrm{OH}$ with the calculated photochemical term in the budget. During the daytime flights, the photochemical loss rate, inferred as the budget residual, averages $7.4 \mathrm{ppthr}^{-1}$. Using the $\mathrm{OH}$ data from PASE, with a daytime mean of $5 \times 10^{6}$ radicals $/ \mathrm{cm}^{3}$ and a maximum that varied between $6 \times 10^{6}$ radicals $/ \mathrm{cm}^{3}$ to as much as $9 \times 10^{6}$ radicals $/ \mathrm{cm}^{3}$, and the DMS $+\mathrm{OH}$ rate constants from Sander et al. (2006), we estimate an 

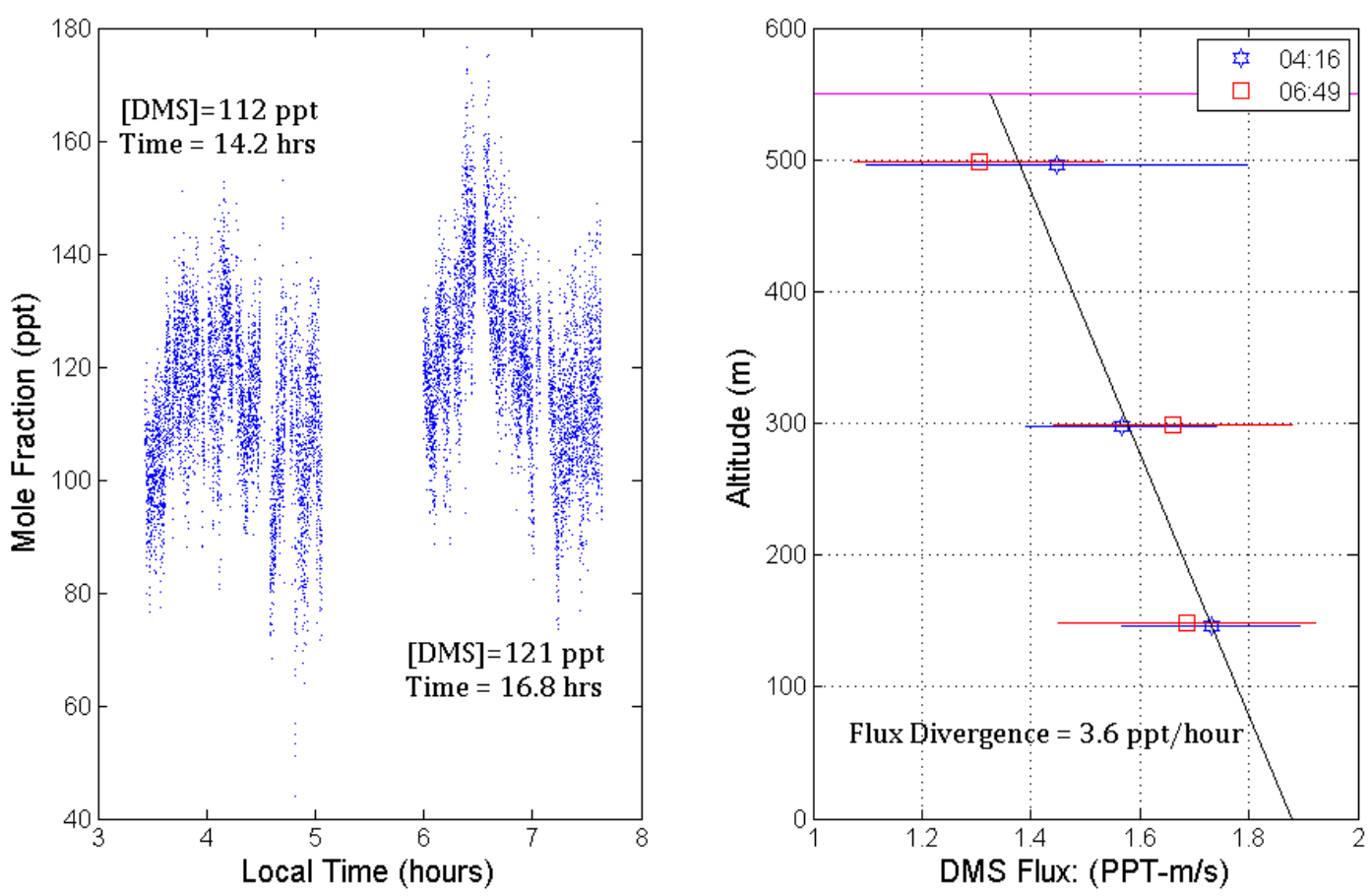

Fig. 8. RF13 DMS concentration (left) and flux profile (right). Between stacks 1 and 2 , the concentration increased by 9 ppt over 2.6 hrs, or $3.5 \mathrm{ppthr}^{-1}$. The right plot shows the flux profile observed on the two predawn stacks (blue stars - between 03:00-05:00, red squares between 05:30-07:30) which indicates an average flux convergence of $3.4 \mathrm{ppthr}^{-1}$.

average daytime loss of DMS to $\mathrm{OH}$ of $7.8 \mathrm{ppthr}^{-1}$. During PEM-Tropics A, measurements of $\mathrm{OH}$ around Christmas Island showed a daily maximum of about $8 \times 10^{6}$ radicals $/ \mathrm{cm}^{3}$ (Chen et al., 2001), which is equivalent to the same daytime mean from PASE.

The atypical flight of the mission (RF14) proves to be the most difficult to understand. The flux of DMS into the buffer layer is significantly larger than the surface flux (1.8 vs. $2.3 \mathrm{ppt} \mathrm{m} \mathrm{s}^{-1}$ ) and the calculated photochemical loss term is about half the predicted loss to $\mathrm{OH}$. This flight was atypical for other reasons as well; the height of the MBL varied temporally during the flight from $\sim 700 \mathrm{~m}$ to $\sim 1200 \mathrm{~m}$, the latter more than double the flight average MBL height. Additionally, the DMS mole fraction for RF14 (94 ppt) was 42\% higher than the daytime average (66 ppt), suggesting that the air mass had recently traveled over very DMS-rich waters which could certainly explain the enhanced flux into the BuL. Clearly, the MBL was far from steady state.

An interesting observation from PASE that could prove useful to model parameterizations is the ratio of surface flux to BuL flux. On average, nearly $77 \%$ of the DMS that enters the MBL from the sea surface during the day is passed through to the overlying buffer layer. This ratio is substantially higher than the $36 \%$ predicted in a modeling study by Lucas and Prinn (2002). In other words, the process of shallow convective pumping of DMS into the BuL and compensating entrainment of low DMS air into the MBL passes most of the surface emissions into the overlying BuL. It is probable that our surface/BuL flux ratio results are biased by the lack of data between sunset and 03:00 a.m., when the MBL concentration would be building up from its minimum value and BuL fluxes would likely have been reduced (see Sect. 4.2). The net entrainment velocities for the PASE flights are compiled in Table 2 with an average value of $1.7 \mathrm{~cm} / \mathrm{s}$ during the day flights, and $2.0 \mathrm{~cm} / \mathrm{s}$ for the night flights. During ACE1, the DMS-derived entrainment velocity varied from $-4 \mathrm{~cm} / \mathrm{s}$ to $+4 \mathrm{~cm} / \mathrm{s}$ (Russell et al., 1998). We should emphasize, however, that the entrainment velocities reported herein are dependent on the exact altitude of any particular BuL leg because of the large gradients in DMS that exist throughout the lower BuL (Fig. 1). Comparisons to other values reported in the literature therefore need to be done with considerable circumspection.

Nighttime flight operations were constrained by the absence of runway lights on Christmas Island. Therefore, flights were required to start late enough at night to ensure landing in full daylight. Consequently, the first MBL legs of the nocturnal flights occurred after 03:00 a.m. As discussed in Sect. 3, the nighttime maximum occurred somewhere around 04:30 a.m., meaning that the night buildup of DMS was nearly complete by the time the aircraft arrived on station. At the time of the first leg on RF06, for instance, the concentration had already stabilized preventing an examination of the expected nighttime buildup. On RF13 


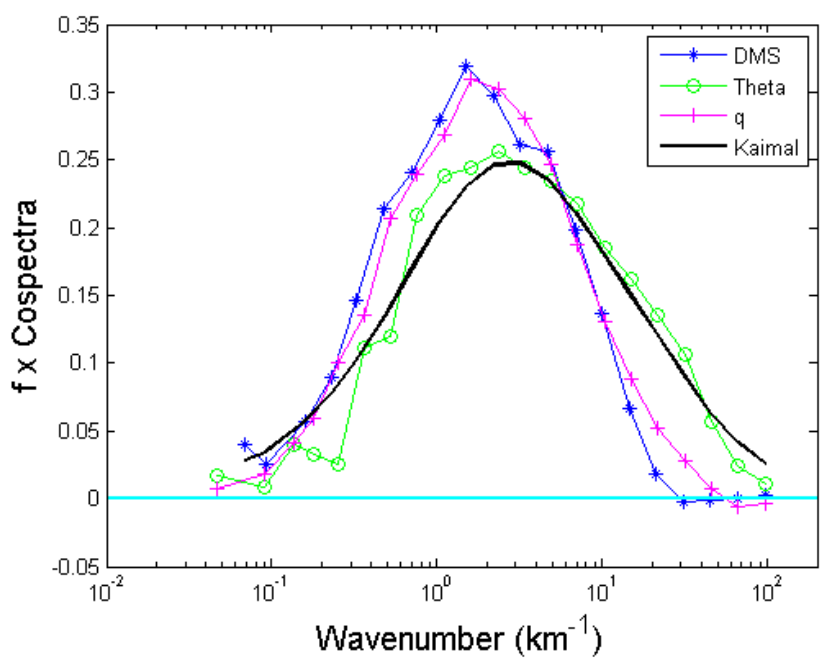

Fig. 9. Averaged Co-Spectra between DMS, potential temperature $(\Theta)$, specific humidity $(q)$, and vertical wind speed $(w)$ for the low level $(z<50 \mathrm{~m})$ legs for all of the PASE flights.

the morning maximum did not occur until nearly 06:30 a.m. (Fig. 8), half way through the second stack. Excluding the third stack, which took place in the early daylight, the observed rate of change was $\sim 3.5 \mathrm{ppthr}^{-1}$. During that dark period, the vertical flux divergence averaged $\sim 3.4 \mathrm{ppthr}^{-1}$. Assuming this flux divergence held throughout the $12 \mathrm{~h}$ of darkness, it would constitute an MBL source of $\sim 40 \mathrm{ppt} / \mathrm{day}$. On average, the MBL DMS mole fraction was observed to decrease by $\sim 35( \pm 5)$ ppt during the daytime flights. Thus we conclude that the flux divergence does indeed compensate for the photochemical destruction in the long term, but more of it occurs diametrically out of phase with destruction, i.e. the buildup occurs during the hours of darkness while the destruction happens during the day.

\subsection{Cospectral similarity}

In the surface layer, passive scalars are often assumed to exhibit a cospectral shape with $w^{\prime}$ that is similar to that of potential temperature $(\Theta)$ (Kaimal et al., 1972). Figure 9 shows the averaged, normalized cospectra for $w$ with DMS, water vapor, and $\Theta$ for all of the flight legs below $50 \mathrm{~m}$ altitude during PASE. The universal Kaimal curve for neutral stability is shown in black and does indeed appear quite similar to $\Theta$, but the peak and much of the covariance occur at higher wavenumber than the cospectra for the other two scalars. Previous investigators using large eddy simulation (LES) also found significant differences in the cospectral shape of $w$ with $\Theta$ and with passive scalars (Jonker et al., 1999). In their simulations it was observed that a principal driving factor in the cospectral distribution among low and high frequencies was the ratio of surface flux to entrainment flux. When the surface/entrainment flux ratio is around -0.5 ,

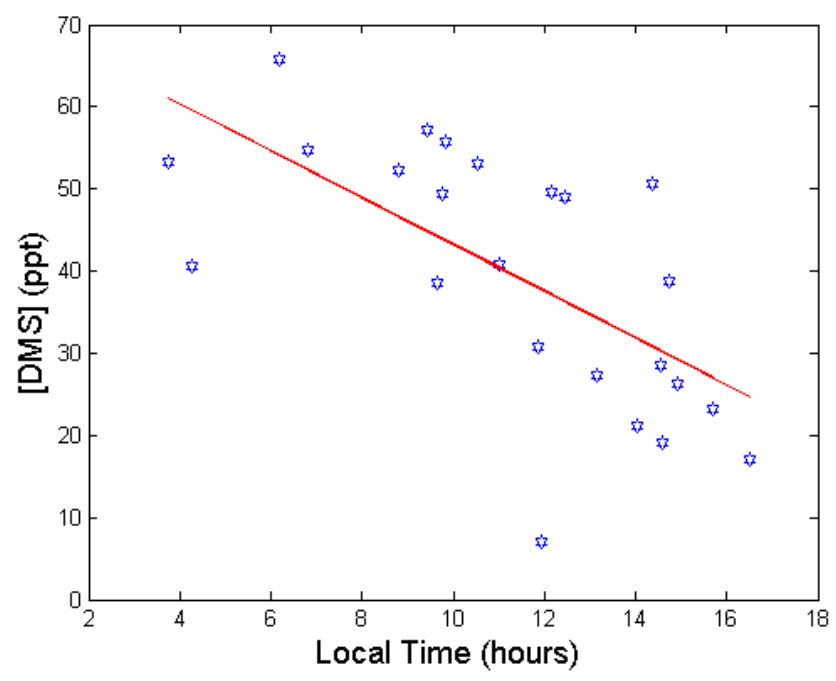

Fig. 10. Difference in DMS concentration between MBL and BuL for all PASE flights by time of day. $R^{2}=0.42$. On average, mean concentration difference decreased at a rate of $=2.8 \mathrm{ppthr}^{-1}$.

the cospectral density is centered towards higher frequencies (similar to $\Theta$ and the universal Kaimal curve). However, when the surface/entrainment flux ratio approaches one, as is the case for water vapor and DMS over the ocean, the transport evolves to larger scales. This topic and detailed characterization of the MBL turbulence will be covered in a subsequent manuscript.

\subsection{Flux profile evolution}

In principle, the evolution of the mean vertical flux divergence in the MBL can be predicted through an examination of the difference between the DMS mixing ratio in the MBL and the BuL. Figure 10 shows the difference as a function of local time for all of the PASE flights. During the daylight hours, any pseudo-first-order photochemical loss is acting to reduce the DMS concentration in both the MBL and the $\mathrm{BuL}$, and assuming similar $\mathrm{OH}$ concentrations in the two layers (Davis et al., 2001; Tan et al., 2001); , each layer will experience the same loss, proportional to the DMS levels, thereby reducing the absolute difference between the layers. Because the entrainment flux is proportional to the absolute concentration difference (assuming that the physical entrainment rate changes gradually over synoptic time scales and not diurnally) the net flux into the BuL will also decrease throughout the day.

The gas transfer velocity for DMS was determined as described by Blomquist et al. (2006), and then the bulk DMS seawater concentration was estimated for each stack by dividing the surface flux by the gas transfer velocity. These concentrations were then plotted as a function of time of day (Fig. 11). It appears that the concentration of DMS at the ocean surface does exhibit a diurnal trend during PASE, 


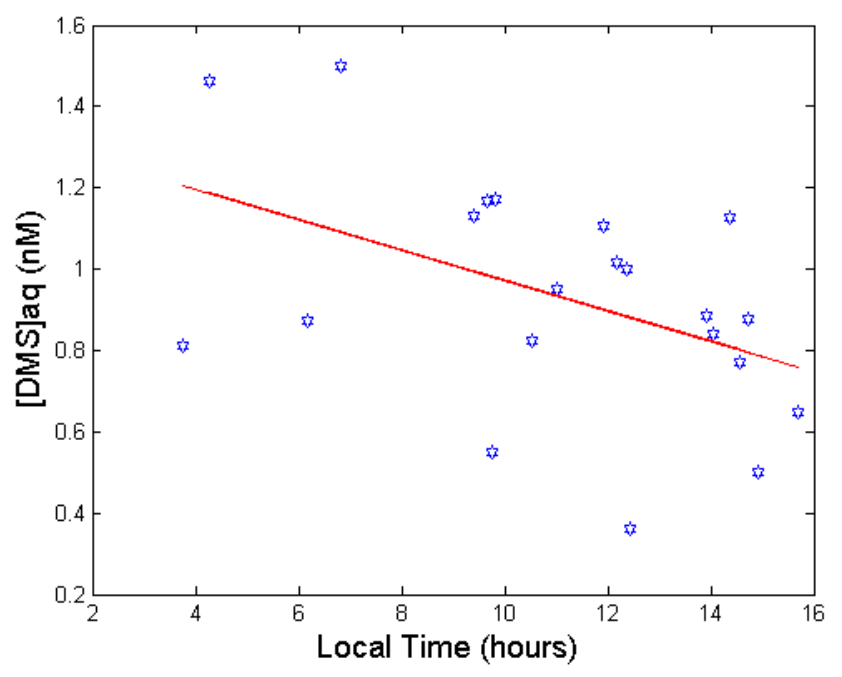

Fig. 11. Surface water DMS concentration estimated from the observed bulk parameterization of Blomquist et al. (2006) for all of the PASE flights as a function of time of day. $R^{2}$ for this plot is 0.22 and the slope is $-0.03 \mathrm{nM} \mathrm{hr}^{-1}$.

declining throughout the day. Although this is not commonly observed (Bailey et al., 2008), we propose that this might be due to solar warming of the ocean surface during the day increasing static stability of the ocean mixed layer, as well as direct photolysis and emission depleting dissolved DMS through the day. Advancing these ideas beyond conjecture, however, would require a careful budget from ship-based measurements to investigate the diurnal pattern in detail.

In any event, both the surface and entrainment fluxes appear to decrease throughout the daytime on average leading to no systematic diurnal pattern in the vertical flux divergence. Because the experimental conditions did not allow for measurements in the late evening, it is not known what happens to the flux divergence term from sunset until $\sim$ 03:00 a.m., but in a diel steady-state sense this term must compensate for daytime photochemical loss in the long run.

\subsection{Error analysis}

When the multiple regression fit returns the solution for Eq. (3), each coefficient is returned along with the expected standard deviation of that coefficient. The net error in the budget table is calculated by adding together all of the errors in Eq. (3) in quadrature. That is, if the matrix $\mathbf{X}$ represents all of the predictor values in the time series i.e., $x, y, z$, then the standard error of the $\mathrm{i}^{\text {th }}$ coefficient $\beta_{i}$ is equal to $\sqrt{M_{i i}}$, where $\boldsymbol{M}=\sigma_{\mathrm{Err}}^{2}\left(\mathbf{X}^{\prime} \mathbf{X}\right)^{-1}$ and $\sigma_{\text {Err }}$ represents the standard deviation of the residuals in the fit. This technique was used to calculate the error in the advection and observed rate of change. The error in the flux divergence term was slightly different because the least squares minimization was performed on the 200 s flux averages, weighted by their standard deviations.
With the exception of RF11 which lacked sufficient flux measurements high in the MBL, the flight budgets all have a net error of $\sim 0.65 \mathrm{ppthr}^{-1}$. Dividing this into the average MBL DMS mole fraction of $\sim 72$ ppt yields a time constant of $\sim 111 \mathrm{~h}$. Therefore, in theory, any physical process that modifies a concentration with a lifetime of $\sim 4.5$ days or less can be detected by the scalar budget method developed in PASE.

\subsection{Comparison to existing parameterizations}

The direct measurements of DMS fluxes made during PASE provide an opportunity to compare the data to predictions of certain parameterizations used in biogeochemical models. For instance, Simo and Dachs (2002) suggest a DMS flux can be estimated from surface chlorophyll concentrations obtained by satellite. The authors propose two regimes based on the ratio of Chlorophyll a $(\mathrm{Chl})$ to the oceanic mixed layer depth (MLD). Mixed layer depth was determined each flight day by examining the temperature profile from the nearest TAO buoy $\left(2^{\circ} \mathrm{N}, 155^{\circ} \mathrm{W}\right)$, which was within $50 \mathrm{~km}$ of the mean position of all the flights. The mixed layer depth increased slightly during the four week mission from $\sim 80 \mathrm{~m}$ on August 10 to $100 \mathrm{~m}$ on 2 September. From Fig. 3, the maximum Chl was $\sim 0.4 \mathrm{mg} / \mathrm{m}^{3}$, equivalent to a maximum value for Chl/MLD of $\sim 0.005 \mathrm{mg} / \mathrm{m}^{4}$, well below the regime where $\mathrm{Chl}$ needs to be considered in predicting the surface DMS concentration.

In this low Chl environment, the surface water DMS concentration predicted by Simo and Dachs (2002) is: $[\mathrm{DMS}]_{a q}=\ln (\mathrm{MLD})+5.7$ which ranges from $1.1 \mathrm{nM}$ to $1.3 \mathrm{nM}$.

We then estimate the flux of DMS from the sea surface using:

$F=[\mathrm{DMS}]_{a q} \cdot k_{w}$

Here, $k_{w}$ is the gas transfer velocity for DMS, estimated to be $12 \mathrm{~cm} \mathrm{hr}^{-1}$ from Fig. 1 of Blomquist et al. (2006) for the typical PASE conditions where the $10 \mathrm{~m}$ horizontal wind speed is $\sim 8 \mathrm{~m} \mathrm{~s}^{-1}$. Given these values, the estimated flux of DMS would be between 3.1 and $3.7 \mu \mathrm{mol} \mathrm{m}^{-2} d^{-1}$, which is in pretty good agreement with the averaged measured surface flux during PASE of $3.0 \mu \mathrm{mol} \mathrm{m}^{-2} \mathrm{~d}^{-1}$.

The average surface flux of $\sim 3.0 \mu \mathrm{mol} \mathrm{m}^{2} \mathrm{day}^{-1}$ observed during PASE is similar to those measured by shipborne eddy covariance in November of 2003 in the eastern equatorial Pacific $\sim 3 \pm 2 \mu \mathrm{mol} / \mathrm{m}^{2}$-day (Huebert et al., 2004), and those inferred from mole fraction measurements made on the coast of Hawaii $\sim 3 \mu \mathrm{mol} / \mathrm{m}^{2}$-day (De Bruyn et al., 2006).

\section{Conclusions}

DMS mole fraction and flux were measured from an aircraft in the remote $\mathrm{MBL}$ near Christmas Island $\left(2^{\circ} \mathrm{N}, 157^{\circ} \mathrm{W}\right)$ 
during the summer of 2007. The expected diurnal pattern of early morning maximum, followed by decay throughout the day to a late afternoon minimum was observed. The mean daytime DMS mole fraction was $\sim 66 \mathrm{ppt}$, while the mean nighttime concentration was $\sim 100 \mathrm{ppt}$. The dynamical terms in the daytime DMS budget (vertical flux divergence and horizontal advection) were found to contribute $1.4 \mathrm{ppthr}^{-1}$ and $0.2 \mathrm{ppthr}^{-1}$, respectively. The average daytime loss rate was $\sim 5.8 \mathrm{ppthr}^{-1}$ leaving an average photochemical loss of $\sim 7.4 \mathrm{ppthr}^{-1}$. The low altitude $(<50 \mathrm{~m})$ cospectral behavior of DMS vs. $w^{\prime}$ was very similar to that of water vs. $w^{\prime}$ but considerably different from potential temperature vs. $w^{\prime}$, which followed the Kaimal (1972) model of cospectra in the surface layer. Using the surface fluxes to estimate the DMS concentration in the surface water, we found evidence of a diurnal cycle in DMS seawater concentration. Further research is required to confirm and understand this cycle as well as the cospectral behavior of DMS vs. $w^{\prime}$.

Acknowledgements. Ocean color data used in this study were produced by the SeaWiFS Project at Goddard Space Flight Center. The data were obtained from the Goddard Earth Sciences Distributed Active Archive Center under the auspices of the National Aeronautics and Space Administration. Use of this data is in accord with the SeaWiFS Research Data Use Terms and Conditions Agreement. Aircraft navigation data and atmospheric state variables provided by NCAR/EOL under sponsorship of the National Science Foundation (http://data.eol.ucar.edu/). Hydroxyl data were kindly provided by R. L. Mauldin. Ocean mixed layer depth was calculated with temperature profiles from TAO buoys, TAO Project Office of NOAA/PMEL. The National Center for Atmospheric Research is sponsored by the National Science Foundation. This work was made possible through a grant from the Atmospheric Chemistry Program of the National Science foundation (ATM-0627227).

Edited by: N. Mihalopoulos

\section{References}

Bailey, K. E., Toole, D. A., Blomquist, B., Najjar, R. G., Huebert, B., Kieber, D. J., Kiene, R. P., Matrai, R., Westby, G. R., and del Valle, D. A.: Dimethylsulfide production in Sargasso Sea eddies, Deep-Sea Res. Pt. II, 55(10-13), 1491-1504, doi:10.1016/j.dsr2.2008.02.011, 2008.

Bandy, A. R., Thornton, D. C., Tu, F. H., Blomquist, B. W., Nadler, W., Mitchell, G. M., and Lenschow, D. H.: Determination of the vertical flux of dimethyl sulfide by eddy correlation and atmospheric pressure ionization mass spectrometry (APIMS), J. Geophys. Res.-Atmos., 107(D24), 4743, doi:10.1029/2002jd002472, 2002.

Blomquist, B. W., Fairall, C. W., Huebert, B. J., Kieber, D. J., and Westby, G. R.: DMS sea-air transfer velocity: Direct measurements by eddy covariance and parameterization based on the NOAA/COARE gas transfer model, Geophys. Res. Lett., 33(7), L07601, doi:10.1029/2006g1025735, 2006.
Blomquist, B. W., Huebert, B. J., and Fairall, C. W.: Determining the sea-air flux of dimethylsulfide by eddy correlation using mass spectrometry, Atmos. Meas. Tech. Discuss., 2, 1973-2025, 2009, http://www.atmos-meas-tech-discuss.net/2/1973/2009/.

Charlson, R. J., Lovelock, J. E., Andreae, M. O., and Warren, S. G.: Oceanic Phytoplankton, Atmospheric Sulfur, Cloud Albedo and Climate, Nature, 326(6114), 655-661, 1987.

Chen, G., Davis, D., Crawford, J., Heikes, B., O'Sullivan, D., Lee, M., Eisele, F., Mauldin, L., Tanner, D., Collins, J., Barrick, J., Anderson, B., Blake, D., Bradshaw, J., Sandholm, S., Carroll, M., Albercook, G., and Clarke, A.: An assessment of HOx chemistry in the tropical Pacific boundary layer: Comparison of model simulations with observations recorded during PEM tropics A, J. Atmos. Chem., 38(3), 317-344, 2001.

Davis, D., Grodzinsky, G., Chen, G., Crawford, J., Eisele, F., Mauldin, L., Tanner, D., Cantrell, C., Brune, W., Tan, D., Faloona, I., Ridley, B., Montzka, D., Walega, J., Grahek, F., Sandholm, S., Sachse, G., Vay, S., Anderson, B., Avery, M., Heikes, B., Snow, J., O'Sullivan, D., Shetter, R., Lefer, B., Blake, D., Blake, N., Carroll, M., and Wang, Y.: Marine latitude/altitude $\mathrm{OH}$ distributions: Comparison of Pacific Ocean observations with models, J. Geophys. Res.-Atmos., 106(D23), 32 691-32 707, 2001.

De Bruyn, W. J., Dahl, E., and Saltzman, E. S.: DMS and SO2 measurements in the tropical marine boundary layer, J. Atmos. Chem., 53(2), 145-154, doi:10.1007/s10874-005-9000-z, 2006.

Faloona, I., Lenschow, D. H., Campos, T., Stevens, B., van Zanten, M., Blomquist, B., Thornton, D., Bandy, A., and Gerber, H.: Observations of entrainment in eastern Pacific marine stratocumulus using three conserved scalars, J. Atmos. Sci., 62(9), 3268-3285, 2005.

Huebert, B. J., Blomquist, B. W., Hare, J. E., Fairall, C. W., Johnson, J. E., and Bates, T. S.: Measurement of the sea-air DMS flux and transfer velocity using eddy correlation, Geophys. Res. Lett., 31(23), L23113, doi10.1029/2004g1021567, 2004.

Jonker, H. J. J., Duynkerke, P. G., and Cuijpers, J. W. M.: Mesoscale fluctuations in scalars generated by boundary layer convection, J. Atmos. Sci., 56(5), 801-808, 1999.

Kaimal, J. C., Izumi, Y., Wyngaard, J. C., and Cote, R.: Spectral Characteristics of Surface-Layer Turbulence, Q. J. Roy. Meteor. Soc., 98(417), 563-589, 1972.

Kowalski, A. S. and Serrano-Ortiz, P.: On the relationship between the eddy covariance, the turbulent flux, and surface exchange for a trace gas such as CO2, Bound.-Lay. Meteorol., 124(2), 129141, doi:10.1007/s10546-007-9171-z, 2007.

Lucas, D. D., and Prinn, R. G.: Mechanistic studies of dimethylsulfide oxidation products using an observationally constrained model, J. Geophys. Res.-Atmos., 107(D14), ACH12-11-26, 4201, doi:10.1029/2001jd000843, 2002.

Nowak, J. B., Davis, D. D., Chen, G., Eisele, F. L., Mauldin, R. L., Tanner, D. J., Cantrell, C., Kosciuch, E., Bandy, A., Thornton, D., and Clarke, A.: Airborne observations of DMSO, DMS, and $\mathrm{OH}$ at marine tropical latitudes, Geophys. Res. Lett., 28(11), 2201-2204, 2001.

Pandis, S. N., Russell, L. M., and Seinfeld, J. H.: The relationship between DMS flux and CCN conecntration in remote marine regions, J. Geophys. Res.-Atmos., 99(D8), 16 945-16 957, 1994.

Russell, L. M., Lenschow, D. H., Laursen, K. K., Krummel, P. B., Siems, S. T., Bandy, A. R., Thornton, D. C., and Bates, T. S.: 
Bidirectional mixing in an ACE 1 marine boundary layer overlain by a second turbulent layer, J. Geophys Res.-Atmos., 103(D13), 16411-16432, 1998.

Sander, S., Golden, D., Kurylo, M., Moortgat, G., and Wine, P.: Chemical Kinetics and Photochemical Data for Use in Atmospheric Studies, JPL Publication, 06(2), 26, 2006.

Simo, R., and Dachs, J.: Global ocean emission of dimethylsulfide predicted from biogeophysical data, Global Biogeochem. Cy., 16(1), 1078, doi:10.1029/2001gb001829, 2002.
Tan, D., Faloona, I., Simpas, J. B., Brune, W., Olson, J., Crawford, J., Avery, M., Sachse, G., Vay, S., Sandholm, S., Guan, H. W., Vaughn, T., Mastromarino, J., Heikes, B., Snow, J., Podolske, J., and Singh, $\mathrm{H} .: \mathrm{OH}$ and $\mathrm{HO} 2$ in the tropical Pacific: Results from PEM-Tropics B, J. Geophys. Res.-Atmos., 106(D23), 32 667$32681,2001$. 